\title{
Concepções de docentes e discentes acerca de metodologias de ensino-aprendizagem: análise do caso do Curso de Enfermagem da Universidade Estadual Vale do Acaraú em Sobral - Ceará
}

Tiago José Silveira Teófilo Maria Socorro de Araújo Dias²

TEÓFILO, T.J.S.; DIAS,M.S.E. Teachers' and students' notions regarding teaching-learning methodologies: analysis on the case of the nursing course at the State University of Vale do Acaraú, in Sobral, Ceará. Interface - Comunic., Saude, Educ., v.13, n.30, p.137-51, jul./set. 2009.

This study sought to ascertain the notions of teachers and students of the nursing course of the State University of Vale do Acaraú regarding teachinglearning methodologies. Data collection took place by means of focus groups of students and teachers and participant observation in classrooms, between June and July 2006. The analysis was guided by hermeneutic-dialectic reference points. The discourse revealed that manifestations of power permeated the pedagogical relationship. Analysis on the divergences and convergences between the discourse revealed that the divergences were within the epistemological field while the convergences came from daily practices. It was inferred that there is a need to incorporate active methodologies and a relationship of dialogue that makes it possible to overcome the established power and the dissonance between theory and practice.

Keywords: Higher education. Nursing education. Teaching-learning methodologies.
Este estudo buscou conhecer a concepção de docentes e discentes do Curso de Enfermagem da Universidade Estadual Vale do Acaraú acerca de metodologias de ensino-aprendizagem. A coleta de dados deu-se por meio de grupos focais com estudantes e professores e observação participante em sala de aula, entre junho e julho de 2006. A análise foi orientada pelo referencial da hermenêutica-dialética. Os discursos revelaram que manifestações de poder permeiam a relação pedagógica. $A$ análise de divergências e convergências entre os discursos revelou que, enquanto as primeiras se inserem no campo epistemológico, as segundas advêm do cotidiano das práticas. Inferiuse a necessidade de incorporação de metodologias ativas e de uma relação dialógica que permita superar o poder estabelecido e a dissonância entre teoria e prática.

Palavras-chave: Ensino superior. Educação em Enfermagem. Metodologias de ensinoaprendizagem. 


\section{Introdução}

A Reforma Sanitária Brasileira representa, desde a década de 1970, um pensamento contrahegemônico que objetiva a transformação/construção do sistema de saúde vigente. Nesse movimento, com a democratização e otimização da Conferência Nacional de Saúde (CNS), em sua oitava edição de 1986, discutiu-se fortemente sobre: a saúde como direito de cidadania, a reforma do Sistema Nacional de Saúde e o seu financiamento. Isto culminou com a criação do Sistema Único de Saúde (SUS), na Constituição de 1988, onde se iniciou uma "reformulação institucional e ideológica" da saúde no Brasil. Assim, ao estabelecer a "saúde como direito de todos e dever do Estado", o princípio central da Reforma Sanitária passa a ser garantido pela Constituição Federal (Andrade, 2002; Brasil, 1988; Conferência Nacional de Saúde, 1986).

Nesta Constituição que ainda vigora, tem-se como atribuição do SUS, no artigo 200, a "ordenação e formação de trabalhadores na área da saúde e o incremento em sua área de atuação ao desenvolvimento científico e tecnológico" (Brasil, 1988, p.145). Contudo, somente na Lei Orgânica da Saúde $n^{\circ} 8.080$, de setembro de 1990 , é que se observa legitimamente um projeto para a formação de profissionais de saúde. Por esta Lei, a União, os Estados, o Distrito Federal e os Municípios participarão na formulação e na execução da política de formação e desenvolvimento dos trabalhadores da saúde no Brasil (Brasil, 2004, 1990).

Desde então, por intermédio das CNS, a ordenação da formação de trabalhadores para a saúde passou a se desenvolver como dispositivo estratégico para a construção/efetivação do SUS. Desta forma, foram criados: programas de capacitação, escolas de saúde pública, sistemas de acompanhamento institucional de projetos de mudança curricular, redes de integração ensino-serviçosociedade, polos de educação permanente em saúde, entre outras ações (Brasil, 2004).

Nesse contexto, ao discorrer sobre a construção histórica do ensino em saúde, limitamos nossa busca à formação de enfermeiros, que, no Brasil, tem seu início de forma sistematizada, apenas na década de 1920.

Até essa data, o ensino básico de enfermagem ainda não tinha caráter de formação superior. Existem registros de atividades de ensino de enfermagem no país apenas no final do século XIX. Contudo, até o início do século XX, essa formação era mormente baseada na necessidade de se constituírem corpos de profissionais de saúde para a guerra, para melhoraria do atendimento hospitalar, e na demanda social de erradicação de doenças da Era Campanhista, a qual buscava garantir o saneamento nos portos. Portanto, o ensino formal de enfermagem é introduzido no Brasil com forte valorização do ensino prático atrelado aos hospitais e de caráter coadjuvante da prática médica (Bonetti, 2004; Kruse, 2002; Germano, 1985).

De acordo com Bonetti (2004), esse sistema hospitalocêntrico de ensino permaneceu hegemônico até meados de 1980, quando ocorreu uma grande mobilização da categoria para construção de um currículo mínimo, que não limitasse o ensino de enfermagem apenas à prática do hospital. Porém, apenas em 1994/5, quando o Ministério da Educação e Cultura propôs os Parâmetros Curriculares Nacionais, este currículo entrou em vigor. O novo currículo, todavia, ainda apresentava muita fragilidade, mantendo o ensino centrado no modelo médico-assistencialista de desarticulação entre conteúdos e disciplinas, de práticas pedagógicas tradicionais de reprodução do conhecimento e de dicotomia entre teoria e prática (Brasil, 1995).

Logo, em 2001, por meio da instituição da Política de Sustentabilidade pela Associação Brasileira de Enfermagem (ABEn) e pelo Ministério da Saúde, articulou-se um movimento nacional de formulação das Diretrizes Curriculares Nacionais (DCN) para os cursos, faculdades e escolas de enfermagem. Essa articulação baseou-se numa multiplicidade de propostas construídas ao longo dos últimos anos, assim como nas propostas de outras áreas (Brasil, 2001).

A formulação das DCN para o Ensino Superior em enfermagem fundamentou-se nas concepções de que tipo de profissional de enfermagem era desejado pela sociedade, pois, tinha-se, até então, a detecção de enfermeiros com perfil inadequado. Isso se deveu, sobretudo, às influências do forte investimento na incorporação de tecnologia e na centralidade do hospital para o desenvolvimento das práticas de saúde e, consequentemente, do ensino das profissões de saúde. Com as mudanças 
dos perfis epidemiológicos e a ampliação dos serviços de atenção básica no SUS, avigorava-se a necessidade de um novo perfil profissional, para além da atenção hospitalar e do uso de equipamentos técnicos (Henriques, Rodrigues, 2003).

Com base nestas diretrizes, os cursos de enfermagem deveriam reformular suas concepções político-pedagógicas em busca de novas construções coerentes com os perfis socioeconômicos e epidemiológicos. Contudo, poucos processos reais de reformulações dos projetos político-pedagógicos, para a formação desse profissional desejado, foram observados no Brasil. Neste processo de qualificar a formação do enfermeiro, acredita-se que deve-se tomar em consideração que se trata da educação de adultos e que, portanto, pressupõe a utilização de metodologias ativas de ensino-aprendizagem.

Tais procedimentos propõem concretamente desafios a serem superados pelos estudantes e docentes, que Ihes possibilitem ocupar o lugar de sujeitos na construção dos conhecimentos, participando da análise do próprio processo assistencial em que estão inseridos e que coloquem o professor como orientador e facilitador desse processo (Brasil, 2004; Rede Unida, 2000).

O processo pedagógico dá-se intimamente entre relações interpessoais e intersubjetivas (as dos estudantes e as dos professores) no processo de educação de adultos. Para entendermos as simetrias e assimetrias destas relações, dialogamos com o conceito de poder de Michel Foucault (2005). Para o autor, o poder não é algo que se possa possuir. Portanto, não existe em nenhuma sociedade divisão entre os que têm e os que não têm poder. "O que faz com que o poder se mantenha e seja aceito é simplesmente porque ele não pesa só como uma força que diz não, mas ele permeia, produz coisas, induz ao pensar, forma saber [...]" (Foucault, 2005, p.12). Pode-se dizer que poder se exerce ou se pratica e o que há são relações e práticas de poder.

Essas práticas circundam o processo de interação entre docentes e discentes, ocorrendo interferência de poder nas relações entre estes, acusando que, na cotidianidade das relações sociais, ocorre corporificação do poder pelas atitudes e, também, por meio dos discursos (Medeiros, 2001).

Corroborando com este ideário, Paulo Freire, em sua extensa obra sobre a Educação (Pedagogia do Oprimido, 1970; Pedagogia da Esperança, 1992; Pedagogia do Diálogo e Conflito, 1995; Pedagogia da Autonomia, 1996), nos direciona para um processo embasado pelo princípio da imunização do bancarismo e da autonomia do ser do educando. Sobre o ensino bancário, Freire (1998, p.25) nos adverte: "quanto mais se exerça a capacidade de aprender tanto mais se constrói e desenvolve o que venho chamando de 'curiosidade epistemológica', sem a qual não alcançamos o conhecimento cabal do objeto [...]". Dessa forma, esta curiosidade nos leva à recusa do ensino "bancário", definido pelo autor como

uma dicotomia inexistente homens-mundo. Homens simplesmente no mundo e não com o mundo e com os outros. Homens expectadores e não criadores do mundo. Concebe a sua consciência como algo especializado e não aos homens como corpos conscientes. A consciência como se fosse alguma seção 'dentro' dos homens, mecanicisticamente compartimentada, passivamente aberta ao mundo que a irá 'enchendo' de realidade. (Freire, 1994, p.36)

Em relação à autonomia do ser do educando, os pressupostos freireanos revelam que

o respeito à autonomia e à dignidade de cada um é um imperativo ético [...] o professor que desrespeita a curiosidade do educando, o seu gosto estético, a sua linguagem, mais precisamente, a sua sintaxe e a sua prosódia [...] transgride os princípios fundamentalmente éticos de nossa existência. (Freire, 1998, p.59-60)

Dessa forma, os papéis compartilhados entre educandos e educadores conduzem a uma relação dialogicamente verdadeira, quando os sujeitos dialógicos aprendem e crescem na diferença.

No processo de ensinar e aprender em saúde, o contexto da supervalorização da técnica tem ocasionado uma aprendizagem superficial, pois muitas vezes esta é posta como um fim em si mesmo. Sendo assim, acredita-se que a memorização de dados embasados na prática da técnica não garante a formulação do pensamento em sua totalidade. Para que ocorra uma aprendizagem significativa é 
necessário criar-se um "processo de interação", um "ambiente pedagógico" e um "jogo pedagógico" onde se consiga ensinar e aprender por meio da formação de sujeitos (Medeiros, 2001).

Percebe-se, então, que, para a formação de enfermeiros ocorrer em consonância com as DCN, é necessário que haja uma mudança no modelo pedagógico utilizado nas escolas de enfermagem. Destacamos, ainda, dois conceitos estudados por diversos autores como objetivos fundamentais na aprendizagem de um curso de graduação: aprender a aprender, que envolve o desenvolvimento de habilidades de busca, seleção e avaliação crítica de dados e informações disponibilizadas em livros, periódicos, bases de dados locais e remotas, além da utilização de fontes pessoais de informação, incluindo, com particular destaque, a informação advinda da própria experiência; e aprender fazendo, que pressupõe a inversão da sequência clássica teoria/prática na produção do conhecimento, e assume que ela ocorre de forma dinâmica por meio da ação-reflexão-ação (Rede Unida, 2000).

Para enriquecer ainda mais a análise proposta neste estudo, buscou-se, na literatura e na pedagogia universitária de forma geral, a compreensão da docência como atividade dialógica. Trabalhando com o processo de ensino universitário, Anastasiou (2003) cria o termo ensinagem para indicar uma prática social complexa efetivada entre os sujeitos, professor e estudante, que engloba tanto a ação de ensinar quanto a de aprender, em processo contratual, de parceria deliberada e consciente para o enfrentamento na construção do conhecimento escolar, resultante de ações efetivadas na / e fora da sala de aula.

A autora complementa que uma ação de ensino da qual resulta a aprendizagem do estudante deve superar o simples dizer do conteúdo por parte do professor, pois é sabido que, na aula tradicional, que se encerra numa simples exposição de tópicos, somente há garantia da citada exposição, e nada se pode afirmar acerca da apreensão do conteúdo pelo aluno. Nessa superação da exposição tradicional, como única forma de explicitar os conteúdos, é que se inserem as estratégias de ensinagem.

O Curso de Enfermagem da Universidade Estadual Vale do Acaraú, lócus de atuação dos autores deste estudo, não se desvia deste percurso traçado pelas escolas de enfermagem no Brasil. Ao se perceberem fragilidades nos processos de mudança político-pedagógica no referido curso, buscou-se, com este estudo, analisar as concepções e práticas dos estudantes e professores no que concerne às metodologias de ensino-aprendizagem.

Como objetivo, teve-se o desafio de contribuir com o processo de mudança na orientação políticopedagógica deste curso, a partir do entendimento de que, ao mesmo tempo em que se conhecem as concepções, logra-se refletir, de forma direta e/ou indireta, com os participantes desse estudo, sobre a socialização-construção de idéias inovadoras e transformadoras.

\section{Metodologia}

Trata-se de um estudo exploratório, descritivo, estratégico, do tipo estudo de caso. É fundamentado por princípios da pesquisa por triangulação de métodos, tendo, como cenário, o Curso de Enfermagem da Universidade Estadual Vale do Acaraú em Sobral - CE. A definição do objeto, bem como do lócus desta investigação, baseou-se nas experiências dos autores, quer como professor quer como estudante deste Curso. Na verdade, ao experimentar-se o processo de ensino-aprendizagem ocorrido no mesmo, inquietou-se com a diversidade de pensamentos e atitudes a respeito do modelo pedagógico utilizado, sendo, portanto, necessário compreender quais as reais concepções de docentes e discentes a respeito das metodologias utilizadas.

Para compreensão de tais concepções, utilizou-se a técnica de grupo focal, também denominada de entrevista grupal. Minayo (1999) refere-se a esta como um excelente método de cunho qualitativo. Para a autora, com o grupo podemos conseguir opiniões relevantes e os valores dos entrevistados. Diferindo, por isso, da observação participante, que focaliza mais o comportamento e as relações. Portanto, acreditou-se que estas duas técnicas se complementavam e, pensando assim, é que se integraram as duas na abordagem do objeto em pauta.

No processo de seleção ou identificação dos sujeitos do grupo focal, buscou-se garantir o que 
nos orienta Minayo (1999, p.146): "valorizar aqueles que podem dispor de informações ímpares, cujo potencial explicativo tem que ser levado em conta". Dessa forma, foram adotados os seguintes critérios de inclusão para os sujeitos do grupo focal: aleatoriamente foram convidados dois grupos de sujeitos: professores e estudantes que integram o curso em questão, sendo, (a) para os discentes - um representante para cada semestre letivo, dos quais se podem encontrar discursos a respeito de todo o processo pedagógico ocorrido nos nove semestres do curso, totalizando nove estudantes; e (b) oito professores, sendo quatro do ciclo básico e quatro do ciclo profissionalizante.

Para a escolha dos professores, considerou-se a quantidade de participantes prevista para o grupo focal de, no mínimo, oito e, no máximo, dez participantes. Portanto, acreditou-se que o número oito fosse ideal para este grupo de implicados, de forma que fosse garantida a qualidade da coleta. Em relação às disciplinas ministradas pelos professores convidados, entendeu-se que era necessário conhecer tanto as concepções daqueles que lecionam as disciplinas práticas como as teóricas, pois, buscou-se desvelar singularidades e peculiaridades das abordagens do processo de ensinoaprendizagem nas aulas teóricas e práticas.

Estes requisitos subsidiaram a formação dos grupos focais. Ressaltamos que reconhecemos como sujeitos desta investigação todos os docentes e discentes do Curso de Enfermagem, uma vez que durante a fase de observação participante in loco - espaço da sala de aula -, o quantitativo destes segmentos observados foi próximo da totalidade.

Ressalvamos, porém, que depois de definidos os critérios e convidados os participantes (foram convidados $1 / 3$ a mais do número previsto), e estes expressarem o livre consentimento de participação, deparamo-nos com número inferior ao previsto. Portanto, na vivência do grupo focal com os discentes, se fizeram presentes sete estudantes, e, no grupo focal com os professores, tivemos a participação de seis. Porém, apesar destas ausências, consideramos relevantes e representativos os discursos dos participantes. Foram realizados, ao todo, dois grupos focais, sendo um para cada categoria de sujeitos.

Com vistas a ampliar as possibilidades de se apreenderem as concepções dos docentes e discentes, a observação participante foi outra técnica de coleta de dados eleita durante todo o processo investigativo. Para Minayo (1999), durante a observação participante é preciso:

Observar o aspecto legal e o aspecto íntimo das relações sociais; ao lado das tradições e costumes, o tom e a importância que lhe são atribuídos; as idéias, os motivos e os sentimentos do grupo na compreensão da totalidade de sua vida, verbalizados por eles próprios, através de suas categorias de pensamento. (Minayo, 1999, p.137-8)

Para realização da observação, não se pretendeu construir um roteiro fechado com questões a serem apreendidas, pois, para a compreensão dos sentimentos, das idéias e dos motivos dos implicados é necessário manter-se aberto a novas nuances que surgem no andar da vida dos mesmos.

É com este intuito que se buscou desenvolver apenas uma rotina de trabalho durante a observação participante, mediante notas e manutenção do diário de campo em vista de autodisciplina. Esta técnica permitiu realizar inferências sobre atitudes dos professores e estudantes durante o processo de ensino-aprendizagem no espaço da sala de aula. A observação não foi orientada por um roteiro sistematizado, esta destinava-se, basicamente: à descrição do processo pedagógico por meio do registro das reações dos estudantes em relação ao método utilizado pelos docentes; ao posicionamento do professor sobre a sua metodologia de ensino e das evidências e limitações de integração/interação docente-discente. Vale destacar que esses pressupostos foram considerados na pesquisa de campo, embora a presente pesquisa não se configure como etnográfica.

Para a concretude desta técnica, elegeram-se seis disciplinas, escolhidas aleatoriamente, sendo três do ciclo básico e três do profissionalizante, pelos mesmos critérios de escolha das disciplinas ministradas pelos docentes do grupo focal. Dessa forma, buscou-se investigar os processos pedagógicos ocorridos tanto nas aulas teóricas como nas práticas. A observação foi realizada nos meses de junho e julho de 2006 nos turnos da manhã, tarde e noite, somando 12 horas por disciplina. Contudo, esta só ocorreu após o consentimento livre do professor e dos estudantes. Vale lembrar que, 
como os autores são membros deste Curso, ao longo do texto, considerar-se-ão as percepções da sua condição na realização da análise.

Para a análise dos resultados, buscou-se aproximação com o referencial da hermenêutica-dialética. Esse método proposto por Minayo (1999, p.245) busca um "caminho do pensamento" com uma via de encontro entre as ciências sociais e a filosofia. Nesse sentido, os passos percorridos após ordenação dos dados empíricos foram: análise linguística dos textos dos autores, identificação dos núcleos de sentidos, interpretação verbal e intelectual dos autores às explicações, além da análise crítica das explicações e interpretações no contexto macroestrutural, no sentido de avançar para um processo de transformação.

Deste modo, com base nos dados empíricos, abstraíram-se dos discursos expressões consideradas como núcleos de sentido, para então se processar a análise. Neste exercício, compreendendo que o texto é mais que um conjunto de partes, buscou-se a explicação e a interpretação da comunicação expressa pelos atores sociais por meio desses núcleos, para, em seguida, se analisarem os espaços extradiscursivos, socioeconômicos e culturais, nos quais estão inseridos os discursos dos diferentes atores sociais (Dias, 2006).

O material obtido pela observação participante foi analisado separadamente, buscando-se descrever situações vivenciadas pelos atores e explicitar determinantes dos comportamentos. Para tanto, discutiram-se os conceitos de alguns dos autores (Foucault, 2005; Medeiros, 2001; Freire, 1994 etc.) escolhidos para diálogo neste estudo.

Declaramos que esta pesquisa atendeu aos procedimentos previstos na Resolução 196/96 do Conselho Nacional de Saúde, tendo sido aprovada previamente pelo Comitê de Ética em Pesquisa da Universidade Estadual Vale do Acaraú.

\section{Compreendendo os sentidos dos discursos dos docentes}

Entendendo que nosso objeto de estudo possui consciência histórica, acreditamos que o grupo social que o constitui - professores e estudantes - é mutável, ou seja, eles estão em constante dinamismo e potencialmente tudo está para ser transformado. Contudo, o pensamento e a consciência são frutos da necessidade, eles não são um ato ou entidade, integram um processo que tem como base a própria construção histórica. Apresentam-se, no quadro a seguir, os textos dos professores e, em seguida, segue a análise (Minayo, 1999). 
Quadro1. Textos dos professores sobre o significado de metodologias de ensino-aprendizagem.

\begin{tabular}{|c|c|c|}
\hline Núcleo de Sentido & Textos & Síntese \\
\hline $\begin{array}{l}\text { As metodologias ativas de } \\
\text { ensino-aprendizagem }\end{array}$ & 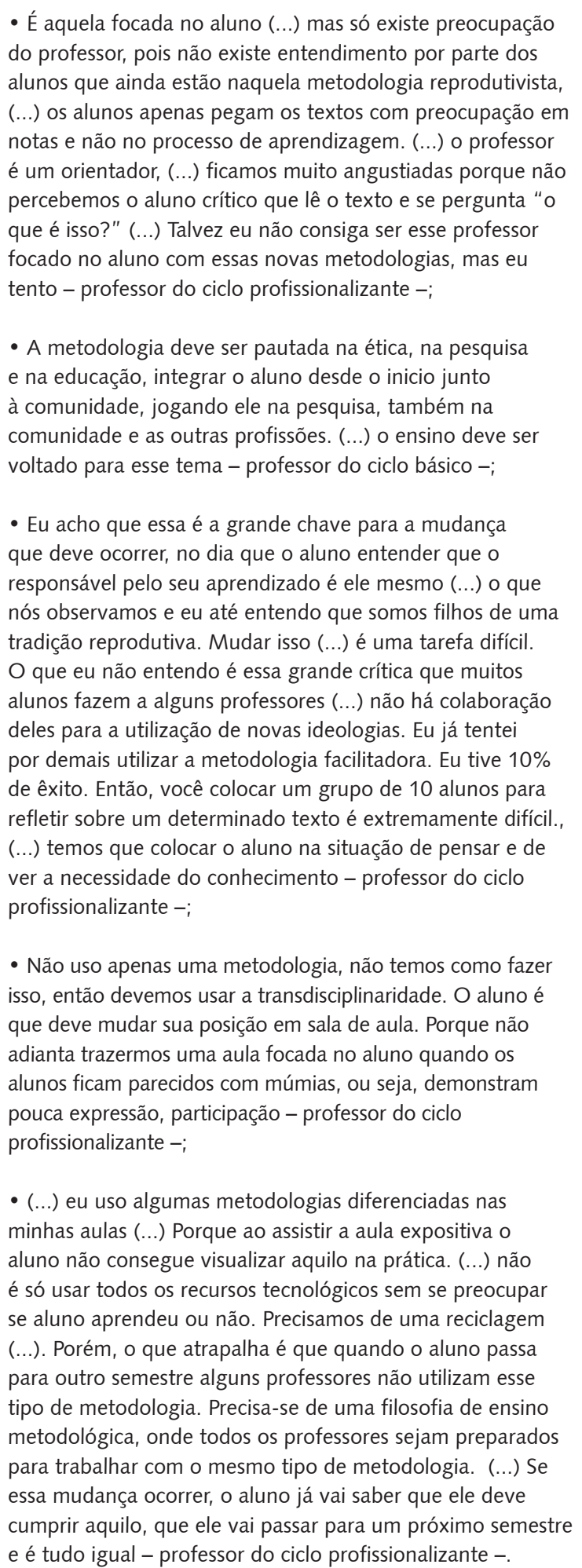 & 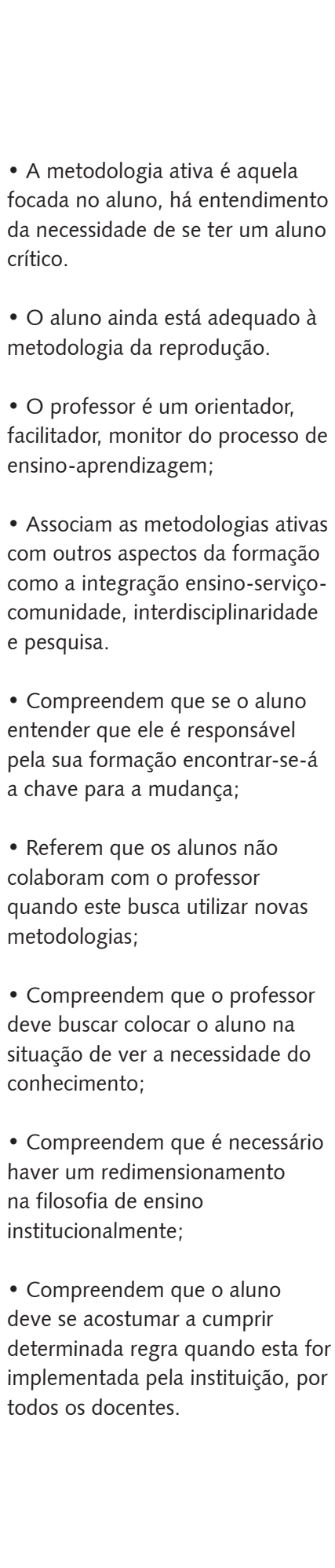 \\
\hline
\end{tabular}


Os discursos docentes, de modo geral, pautam-se, sobretudo, em questões singulares vivenciadas em sua prática individual, porém, identificamos também textos referentes às necessidades institucionais. Compreende-se, dessa forma, que os discursos são ricos de significados, nos quais se puderam encontrar tanto situações particulares dos professores como da instituição da qual fazem parte, ou seja, o Curso de Enfermagem.

Em relação às metodologias de ensino-aprendizagem, observou-se que as concepções docentes se encaminham para a crítica, ou seja, buscam incorporar algumas tendências que impulsionam a transformação. As expressões: focada no aluno; aluno crítico; visão construtivista, e posição de pensar e de ver a necessidade do conhecimento denotam a busca docente pela "imunização do bancarismo", na qual o educador busca construir uma verdadeira aprendizagem significativa (Freire, 1998, p.19).

Isso pode ser observado também nos discursos a respeito da responsabilidade do professor no processo de ensinar e de aprender, como vemos nos seguintes enunciados: o professor é um orientador; o professor é um monitor [...] um instrutor. Estes revelam que os docentes sinalizam referenciais norteadores de práticas inovadoras, mas reconhecem o seu papel de orientador de um processo e não expressam considerar determinados sistemas de correlações de forças.

Para Medeiros (2001), aprender a ser crítico, independente e autônomo, equivale a dizer tornar-se capaz de realizar aprendizagens significativas situadas em uma ampla gama de situações e circunstâncias. Para a autora, o compromisso das instituições universitárias no processo de emancipação de sujeitos é o de outorgar a aprendizagem da aquisição de estratégias cognitivas, que, por sua vez, são formadas por esquemas de aprender a aprender em suas diferenças.

Mesmo reconhecendo ser a proposta de construção de sujeitos a ideal para a formação de enfermeiros, os professores relatam se deparar com muitas dificuldades no processo de incorporação desses pressupostos. Para os docentes, essas dificuldades se devem, sobretudo, à resistência discente ou, mesmo, ao ideal "reprodutivista" destes, como se observa nas falas:

não entendo [...] essa grande crítica que muitos alunos fazem a alguns professores [...] não há colaboração deles para a utilização de novas ideologias;

não adianta trazermos uma aula focada no aluno quando alguns alunos ficam parecidos com múmias, ou seja, demonstram pouca expressão e participação.

Tentando compreender o "contexto" existente no "texto" dos docentes, entende-se como desafiador o processo vivenciado por um estudante, que teve sua formação escolar baseada, sobretudo, no ensino bancário, em um sujeito participante do seu próprio processo de aprendizagem. Infere-se ainda que, de certa forma, é atribuída, ao estudante, a "culpa" pelo fracasso nas interações pedagógicas que se destinam à construção de sujeitos por meio de metodologias ativas.

Nesse sentido, acredita-se que os docentes se contradizem em seus discursos, pois, como poderão facilitar a aprendizagem de sujeitos que consideram rígidos para a mudança, se os sujeitos não se corresponsabilizarem pelo processo de ensino-aprendizagem? Acredita-se que existam limitações nas proposições progressistas de ensinar e de aprender adotadas pelos docentes, por não tentarem visualizar, também, a aprendizagem das emoções, dos limites e, certamente, das potencialidades.

Tornar o estudante capaz de aprender a aprender é tarefa árdua, porém, Freire (1998, p.29) mostra que isso só é possível na "presença de educadores e de educandos criadores, instigadores, inquietos, rigorosamente curiosos, humildes e persistentes". O autor enriquece essa discussão mostrando que o ensinar exige convicção de que a mudança é possível, pois o mundo não é o mundo, está sendo, e não somos somente objetos da história, mas seu sujeito igualmente.

A compreensão dos pressupostos referentes às críticas à formação dos profissionais de saúde é essencial para se almejar a utilização de metodologias ativas de ensino-aprendizagem. São primordiais: o entendimento da necessidade de se ampliarem os espaços de ensino-aprendizagem (integração ensino-serviço); a participação da comunidade no processo de formaçãa; as abordagens integradoras com outras áreas do conhecimento, e a indissociabilidade do ensino, da pesquisa e da extensão. Este entendimento é explicitado, ainda que superficialmente, no seguinte discurso: a metodologia deve ser 
pautada na ética, na pesquisa e na educação, integrar o aluno desde o início junto à comunidade, [...] e às outras profissões.

Outro fator importante nos discursos docentes se refere às necessidades institucionais de organização que se destinam à efetivação de ideais metodológicos em busca da crítica. Os textos seguintes sinalizam nesta direção de construção de sujeitos: [...] não é só usar todos os recursos tecnológicos sem se preocupar se aluno aprendeu ou não, precisa-se de uma filosofia de ensino [...] onde todos os professores sejam preparados para trabalhar com o mesmo tipo de metodologia.

Observa-se também que, neste mesmo discurso, existe fragilidade na proposta, pois o modo "impositivo" com que o professor se expressa, ou seja, à medida que percebe a necessidade de mudança, ao acreditar que "todos" devem se adequar rigidamente a determinados pressupostos metodológicos, exclui a importância do individual, ou limita os espaços de construção crítica e reflexiva no coletivo. O recorte discursivo, a seguir, reforça a idéia de submissão dos estudantes ao método, na concepção docente: [...] o aluno já vai saber que ele deve cumprir aquilo, que ele vai passar para um próximo semestre, e é tudo igual. Assim, a solução encontrada para o problema da não adesão dos estudantes seria impor-lhes uma maneira de ser, e não construir com estes o caminho.

A complexidade de um processo de mudança de concepções é imensa e exige, dos sujeitos interessados, paciência e perseverança, pois são as pessoas que devem ter suas práticas ressignificadas. Sendo assim, essa nova forma de pensar o conhecimento, por meio do modelo de ensino pressupõe uma nova "cultura" pedagógica a ser incorporada pelas pessoas que constituem a instituição. Os estudantes são membros da instituição de ensino e devem fazer parte desse processo ativamente.

Neste sentido, concordamos com Medeiros (2001), quando refere que o compromisso de exercer o ensinar e o aprender pode permanecer nas relações distantes e rígidas onde, neste caso, a reprodução social está garantida. Porém, se esse compromisso eclodir em formas criativas, os caminhos não condenarão as possibilidades do desenvolvimento das capacidades humanas.

\section{As concepções discentes: adentrando nos discursos de quem é formado, se forma e forma}

Ingressando no mundo dos estudantes, percebemos nos contextos dos discursos, revelações enriquecedoras para a compreensão das concepções do "novo" no processo de ensinar e aprender a partir de suas visões de mundo. O quadro a seguir traz recortes dos discursos discentes. 
Quadro 2. Textos dos estudantes sobre o significado de metodologias de ensino-aprendizagem.

\begin{tabular}{|c|c|c|}
\hline Núcleo de Sentido & Textos & Síntese \\
\hline $\begin{array}{l}\text { O significado de } \\
\text { metodologias de } \\
\text { ensino-aprendizagem }\end{array}$ & $\begin{array}{l}\text { - A metodologia é a forma como você chega a uma } \\
\text { determinada coisa, ou seja, quais os procedimentos } \\
\text { necessários para você atingir seu objetivo; } \\
\text { - Na metodologia tradicional, o professor fala e o estudante } \\
\text { só escuta, não há um debate do tema (...) a metodologia } \\
\text { ativa é muito importante porque além de ser mais fácil para } \\
\text { o aprendizado (...) pois não é aquela que você só escuta e } \\
\text { se cansa, não aprende, não discute, não expõe suas idéias, } \\
\text { porque todo mundo tem um consentimento prévio sobre } \\
\text { qualquer assunto (...) o professor como orientador deve } \\
\text { conduzir o estudante nesse caminho (...). } \\
\text { - O contato professor-aluno é muito importante (...) o } \\
\text { professor também deve aprender com o aluno, assim, } \\
\text { essas metodologias de discussão, de debate, são muito } \\
\text { interessantes, pois agente tem liberdade para perguntar o } \\
\text { que quiser. } \\
\text { - Alguns professores tentam utilizar essas metodologias, mas } \\
\text { ainda usam de uma forma, não errada, mas de uma forma } \\
\text { acomodada, (...) não existe aquela troca (...) às vezes parece } \\
\text { que o professor está enchendo lingüiça (...). } \\
\text { - existem professores que sabem muito, mas não sabem } \\
\text { repassar por que não tem uma boa didática (...) a } \\
\text { metodologia ativa combina mais com as disciplinas práticas } \\
\text { (...). } \\
\text { qualifiquem (...) eles têm suas aulas prontas para todos os } \\
\text { semestres e não tentam inovar, buscar atualidades (...) a } \\
\text { - existe um professor que tem uma forma tradicional de } \\
\text { ensinar, usando aulas expositivas, algumas pessoas até } \\
\text { reclamam porque não se consegue fazer perguntas, pois o } \\
\text { professor é desagradável, mas eu considero esse professor } \\
\text { o melhor da faculdade, embora sua metodologia seja } \\
\text { os assuntos impos erros (...). } \\
\text { forma de dar aula (...). } \\
\text { }\end{array}$ & $\begin{array}{l}\text { - Compreendem que a } \\
\text { metodologia tradicional se baseia } \\
\text { em aulas expositivas e ausência de } \\
\text { participação dos estudantes; } \\
\text { - Compreendem as metodologias } \\
\text { ativas de ensino-aprendizagem } \\
\text { como aquelas que são dinâmicas, } \\
\text { dão espaço ao estudante, buscam } \\
\text { o diálogo e destinam-se à troca. } \\
\text { - Compreendem a importância } \\
\text { das relações / interações } \\
\text { professor-estudante no processo } \\
\text { de ensino-aprendizagem; } \\
\text { - Compreendem que existem } \\
\text { professores que tentam incorporar } \\
\text { as metodologias ativas, mas se } \\
\text { acomodam no processo e não } \\
\text { permitem que o estudante se } \\
\text { expresse significativamente. } \\
\text { - Compreensão de que a didática } \\
\text { do professor é importante para o } \\
\text { processo de ensinar e aprender. } \\
\text { - Valorizam aspectos das } \\
\text { metodologias tradicionais, como a } \\
\text { maneira de dar aulas expositivas e } \\
\text { didática particular de determinados } \\
\text { professores. }\end{array}$ \\
\hline
\end{tabular}

Nos discursos dos estudantes, as concepções de metodologias de ensino-aprendizagem se baseiam na diferenciação entre as tradicionais e as ativas. Para as metodologias ativas, os protocolos de discurso trazem novas perspectivas para a aprendizagem significativa. Ocorre que, para os estudantes, estas metodologias utilizam meios democráticos de interação pedagógica, como podemos perceber nos textos: as metodologias de discussão, de debate, são muito interessantes, pois a gente tem liberdade para perguntar o que quiser; o contato professor-aluno é muito importante; a metodologia ativa [...], o professor como orientador deve conduzir o estudante nesse caminho. 
Pode-se visualizar que os estudantes acreditam que as metodologias ativas geram espaços democráticos. Nestes, os mesmos são considerados sujeitos que compartilham informações e buscam a aprendizagem significativa por meio da discussão e da troca de saberes. Identificou-se, nos argumentos discentes, uma consciência da necessidade de estratégias que se destinem à interação entre professor-estudante e o objeto do conhecimento em sua razão de ser, seu significado.

Os estudantes expressam que as metodologias tradicionais têm cumprido o papel da transmissão de conteúdos por intermédio de aulas expositivas, pois estes não têm espaço para construir seu próprio conhecimento. Todavia, nos argumentos dos estudantes investigados, fica clara certa valorização dada a alguns aspectos das metodologias tradicionais, como a maneira de dar aulas expositivas e a didática particular de alguns professores, a qual eles mesmos reconhecem: existe um professor que tem uma forma tradicional de ensinar [...] mas eu considero esse professor o melhor da faculdade [...] ele usa uma didática excelente.

Compreende-se, por meio destes discursos, que os estudantes avaliam, como importantes, os espaços de transmissão de conteúdos, pois mesmo criticando-os e reconhecendo outras maneiras de conduzir o processo de ensino-aprendizagem, relatam ser esse um momento onde os docentes, com suas didáticas "mágicas", conseguem expor os conteúdos de forma que o estudante, calado, interiorize as informações.

Para explicar tal fenômeno, Anastasiou (2003) mostra que, mesmo numa situação que tradicionalmente seja considerada "uma boa aula", em geral, explicita-se o conteúdo da disciplina com suas definições ou sínteses, desconsiderando-se os elementos históricos e contextuais, muitas vezes tomando suas sínteses temporárias como definitivas, desconectando-as de afirmações técnicas das pesquisas científicas que as originaram. Além disso, toma-se, assim, a simples transmissão da informação como ensino, e o professor fica como fonte de saber, tornando-se o portador e a garantia da verdade.

Parafraseando Reboul (1982, p.27), a autora supracitada acredita que o estudante habitua-se a crer que existe uma 'língua do professor', a qual tem de ser aceita, mesmo sem ser compreendida, e a contentar-se, dessa forma, com as fórmulas mágicas ditadas pelo professor. Nesse processo, ficam excluídas as historicidades, os determinantes, os nexos internos, a rede teórica, enfim, os elementos que possibilitaram aquela síntese obtida; a ausência desses aspectos científicos, sociais e históricos deixa os conteúdos "soltos", fragmentados, com fim em si mesmo.

Para Bordenave (1984 apud Sena-Chompré, Egry, 1998), a concepção pedagógica de transmissão tem como elementos principais, no processo educativo, a experiência fundamental que o estudante deve viver para alcançar seus objetivos: o recebimento do que o professor e os livros the oferecem, o que esvaece o verdadeiro papel do docente e do discente e dificulta a atitude de mudança de comportamento para as concepções problematizadoras (ativas), onde a pessoa é considerada em sua totalidade como um agente de transformação.

Ao se vislumbrar, porém, a totalidade dos discursos discentes, compreende-se que a idéia central trazida pelos estudantes, sobre a construção do saber por meio de metodologias ativas, deposita-se na compreensão da importância dos processos de discussão, advindos das intervenções e interações pedagógicas e na efetivação de um processo de ensinagem. Essa postura tranquilizadora, de certa forma prevalente, remete ao fato de haver entre os estudantes espaço para a crítica e, ao mesmo tempo, denuncia a valorização da técnica que ainda transita livremente no cotidiano do ensinar e aprender (Anastasiou, 2003; Medeiros, 2001).

Em síntese, a compreensão de metodologias de ensino-aprendizagem pelos discentes perpassa por questões clássicas, como a necessidade: de incorporação de novos conhecimentos pedagógicos por parte dos docentes, da redefinição dos papéis dos estudantes e docentes, da valorização da transmissão de conteúdos prontos, e da limitação da aprendizagem por meio de estruturas rígidas nas relações interpessoais.

\section{O processo pedagógico vivenciado: a práxis no espaço da sala de aula}

O desafio de encontrar, nas arestas da complexidade da vida humana, as atitudes que denotam a determinação social dos fatos é uma tarefa difícil. Ao se realizar observação participante nas salas de 
aula, nas quais os autores deste estudo também são atores, buscou-se, por meio da visualização das relações interpessoais, vincular os fatos às suas representações e contradições.

Por intermédio do espaço da sala de aula, visualizaram-se diversas situações que ajudam a compreender a ideologia que fundamenta a prática pedagógica usada para a formação de profissionais de enfermagem. Mesmo concordando com a necessidade de se ampliarem os espaços de ensinoaprendizagem, acredita-se, porém, que a sala de aula representa um lugar que possibilita uma relação pedagógica capaz de gerar momentos de aprendizagem significativa.

Para Medeiros (2001), as práticas exercidas nas salas de aula estão solidificadas em relações cristalizadas, muito especialmente pela saliência histórica do imperar da técnica em detrimento da crítica. No âmbito da sala de aula, o desenvolvimento de processos interativos/interpessoais constitui, por meio da linguagem, o fato pedagógico. Sendo assim, o espaço da sala de aula é um meio social que define e (re) define profundamente a efetivação das idéias comunicadas.

Nos espaços da sala de aula, encontramos diferentes momentos de interação social docentediscente que sinalizam mais para o fortalecimento de estruturas rígidas - onde o docente determina sozinho como se dará o processo e qual o papel de cada um - do que espaços de interação democrática efetiva. Em poucos momentos evidenciamos interação eficaz, ou seja, a interação foi percebida apenas no aspecto pedagógico. Os fenômenos observados, que geram essa inferência, estão baseados, por exemplo: no desconhecimento dos nomes individuais dos estudantes, nas atitudes autoritárias por parte dos docentes diante dos conflitos, na definição das atividades e na forma como os conteúdos deveriam ser estudados e compreendidos.

Medeiros (2001) nos esclarece que é, dessa forma, que o professor tradicional se isenta de riscos, porque o estudante não expõe suas idéias e fragilidades em função da inocuidade da relação pedagógica que desencoraja a crítica, o crescimento e o desenvolvimento intelectuais. Nessa relação, o estudante deve respeito ao professor, se quiser gozar de uma falsa liberdade.

Diante disso, as aulas expositivas, os métodos pedagógicos de transmissão - com as transparências, os slides e o volume excessivo de conteúdos - prevalecem definindo a prática pedagógica tradicional, positivista. Acredita-se que este modelo, porém, em sua essência, é incapaz de construir competências efetivas de modo a garantir o entendimento do ser humano em sua integralidade, para a intervenção no processo saúde-doença.

Compreende-se que o cuidado oportuno deve ser livre de risco, integral e contínuo, a todas as pessoas, independente de sua classe social, raça ou etnia, dando-lhes direito à felicidade. Portanto, diante do imenso desafio do ensinar a cuidar, faz-se necessário ampliarem-se os horizontes pedagógicos incorporados na prática dos docentes e profissionais de enfermagem, balizando uma visão ampla na compreensão dos determinantes sociais do processo saúde-doença (Sena-Shompre, Egry, 1998).

Poucas vezes os docentes, por meio do diálogo aberto, tentam trazer problemas que são essenciais para a construção de um conhecimento com totalidade. Nestas poucas tentativas, a divisão da turma em pequenos grupos, para discussão em torno de problemas comuns, mostra uma libertação do mero preparo de conteúdos para exposição. A busca pela funcionalidade do que é aprendido, dessa forma, torna-se mais palpável. Porém, uma das explicações para a fragilidade observada nesta iniciativa está na inexistência de discussões acerca da abordagem pedagógica com os estudantes.

Por sua vez, os estudantes tornam-se alheios aos pressupostos epistemológicos construtivistas de ensino-aprendizagem. Acredita-se que, por isso, ainda haja resistência, por parte de alguns estudantes, na aceitação das metodologias ativas, já que as verdadeiras mudanças não se efetivam sem resistências, dúvidas, medos e conflitos.

No espaço da sala de aula, ocorre o que Medeiros (2001) considera de "jogo pedagógico". Na vivência deste jogo no curso de graduação em questão, as movimentações cotidianas dos sujeitos são concretamente infindáveis e cheias de significado. São geradoras de simetrias e assimetrias, mas as singularidades e peculiaridades de cada indivíduo vão definindo o controle de divergências pelo / e no coletivo, embora alguns ainda exerçam controle e submissão sobre os outros, interferindo e rebuscando os atos de aprendizagem. 


\section{O convergente e o divergente entre os discursos: proposições para um processo de transformação}

A busca pelo entendimento dos contextos expressos nos discursos discentes cruza por questões relacionadas aos discursos docentes, e vice-versa, por meio dos sentidos expressos por ambos. Encontramos, nesses discursos, profundas manifestações das relações de poder que permeiam a sala de aula, onde os estudantes, mesmo reconhecendo que os docentes pouco interagem, não dão espaço e não sinalizam para a mudança, se mostram valorizadores de estruturas pedagógicas bancárias.

Esse aspecto converge com algumas proposições dos discursos docentes ao relatarem haver uma resistência por parte dos discentes na incorporação de metodologias ativas de ensino-aprendizagem. Porém, acreditamos que há divergência em parte dessa proposição. Ocorre que os professores visualizam os estudantes, que possuem consciência histórica, como pessoas isentas de crítica e de proposições acerca do processo de ensinar e aprender.

Por este fato, os docentes não estão levando em consideração que, embora alguns discentes valorizem aspectos reprodutivistas - muito provavelmente presentes em suas histórias desde o Ensino Fundamental --, muitos buscam mudanças, pois, como observado em seus discursos, acreditam nos espaços democráticos de construção do conhecimento.

Neste ínterim, inferiu-se a necessidade de incorporação de metodologias ativas e de uma relação dialógica que permita superar o poder estabelecido e a consequente dissonância entre teoria e prática.

Após a realização dessa busca de sentidos nos discursos e na vivência dos sujeitos que formam o Curso de Enfermagem, apresenta-se uma discussão sobre o processo de transformação, que se acredita representar apenas um pequeno passo para a real mudança que deve ocorrer na formação de enfermeiros.

Compreende-se que os discursos são constituídos com base em construções históricas, com influências do modelo sociopolítico, econômico e cultural das contradições sociais, e, por isso, no campo da educação, a realidade tem sido vista, muitas vezes, de forma objetiva e neutra, onde o ser humano é considerado uma "ferramenta" a ser "lapidada", o que compõe o pensamento positivista.

Acredita-se, dessa forma, que a mudança na formação de enfermeiros deve ocorrer de maneira interligada com as transformações do processo de construção do SUS, onde as representações do processo saúde-doença são percebidas como fenômenos sociais historicamente determinados. Sabese que essa mudança de paradigma não pode se dar apenas nas instituições e escolas de saúde, pois a ressignificação da saúde e da doença perpassa por todos os homens, que, possuindo consciência histórica, estão condicionados aos fatores sociais, políticos e econômicos.

A formação de um profissional comprometido com a efetivação dessa mudança é um desafio com o qual as políticas públicas de saúde no Brasil têm se deparado. Neste sentido, a reconfiguração dos processos de ensino-aprendizagem nas escolas de enfermagem está intimamente ligada à própria construção histórica dessa área na saúde. A enfermagem, em muitos aspectos, tem caminhado junto aos conceitos "modernizantes" de saúde, por meio do incremento de tecnologias duras, em detrimento do cuidado com as tecnologias leves. Este modelo ideológico tradicional conserva as relações verticalizadas entre os profissionais e a população, e por isso a profissão necessita repensar seu fazer construindo e sistematizando as novas práticas que incorporam a totalidade das ações de promoção e prevenção, combinadas às ações de controle do estado de saúde destinadas à reabilitação.

$\mathrm{Na}$ verdade, uma proposição para a mudança que se restrinja apenas às discussões a respeito do ato pedagógico não pode ser efetiva. Acreditamos que as práticas pedagógicas tecnificadas estão presentes nas relações entre os sujeitos nas escolas de enfermagem, e que tal fato se deve à resistência, à alienação e à ingenuidade de docentes, pois julgam que suas técnicas rígidas podem superar os problemas historicamente constituídos.

Sendo assim, para concluir, lembramos que a transformação da educação dos profissionais de enfermagem, que não está limitada às mudanças apenas no fator pedagógico mediado entre docentes e discentes, perpassa por muitas outras atitudes inovadoras, que, como podemos visualizar na totalidade da formação, se complementam e se adicionam.

Referimos-nos à necessidade de mudanças nas relações entre serviços, universidade e comunidade, 
onde devem ocorrer efetivamente os momentos de formação de profissionais de saúde. Para tanto, não podemos nos limitar a discutir e rediscutir o processo de ensino-aprendizagem sem adentrarmos nos espaços dos serviços de saúde e da comunidade. Esse adentramento deve ultrapassar os objetivos que vêm sendo postos pela extensão e pelos estágios e aulas práticas, ou seja, uma parceria concreta entre a universidade, comunidade e serviços, que gera reflexão, que gera ação transformadora.

Portanto, se as interações intersubjetivas considerarem o ser humano em sua integralidade, o modelo de ensinar o aprender a aprender se transforma por meio dessas parcerias. Essa transformação pode ocorrer à medida que são reconcebidas as concepções de vida, sociedade, homem, saúde, doença, educação, cultura, intersetorialidade, integração, poder, solidariedade e democracia.

\section{Colaboradores}

Os autores trabalharam juntos em todas as etapas de produção do manuscrito.

\section{Referências}

ANASTASIOU, L.G.C. Ensinar, aprender, e processos de ensinagem. 2003. Disponível em: <www.fcf.usp.br/Ensino/Graduacao/Disciplinas/Exclusivo/Inserir/Anexos/ LinkAnexos/CAPÍTULO\%201\%20LeaAnastasiou.pdf>. Acesso em: 12 set. 2008.

ANDRADE, L.O.M. Sistema de salud de Brasil: normas, gestión y financiamiento. São Paulo: Hucitec, 2002.

BONETTI, O.P. A formação que temos e a formação que queremos: discursos acerca da formação em enfermagem. 2004. Trabalho de conclusão de curso (Graduação em Enfermagem) - Escola de Enfermagem, Universidade Federal do Rio Grande do Sul, Porto Alegre. 2004.

BRASIL. Secretaria de Gestão do Trabalho e da Educação na Saúde. Departamento de Gestão da Educação na Saúde. Educar SUS: notas sobre o desempenho do Departamento de Gestão da Educação na Saúde - período de janeiro de 2003 a janeiro de 2004. Brasília: Ministério da Saúde, 2004.

Ministério da Educação. Conselho Nacional de Educação. Câmara de Educação Superior. Resolução CNE/CES n 3, de 07 de novembro de 2001. Diretrizes Curriculares Nacionais do Curso de Graduação em Enfermagem. Braślia: Ministério da Saúde, 2001.

Ministério da Educação. Conselho Nacional de Educação. Parâmetros Curriculares Nacionais: versão preliminar. Brasília: Ministério da Saúde, 1995.

Lei Orgânica da Saúde. Lei n 8.080, de 19 de setembro de 1990. Diário Oficial da União, Brasília, DF, 20 set. 1990. Disponível em: <http://www010.dataprev.gov.br/ sislex/paginas/42/1990/8080.htm > . Acesso em: 12 dez. 2005.

Constituição da República Federativa do Brasil de 1988. Brasília: MP Editora, 1988.

CONFERÊNCIA NACIONAL DE SAÚDE, 8. Relatório final. Brasília: 10-12 de

Outubro de 1986. Disponível em: <conselho.saude.gov.br/biblioteca/Relatorios/

relatoriolconferencianacionaldesaudebnucal.doc>. Acesso em: 23 abr. 2006.

DELLAROZA, M.S.G.; VANNUCHI, M.T.O. O currículo integrado do curso de Enfermagem da Universidade Estadual de Londrina: do sonho à realidade. São Paulo: Hucitec, 2005. 
DIAS, M.S.A. O semblante da clínica dialítica no contexto da promoção da saúde: concepções dos profissionais de saúde sobre sua práxis. 2006. Tese (Doutorado) - Curso de Enfermagem, Universidade Federal do Ceará, Fortaleza. 2006.

FOUCAULT, M. Microfísica do poder. 21.ed. São Paulo: Paz e Terra, 2005.

FREIRE, P. Pedagogia da autonomia. São Paulo: Paz e Terra, 1998. Pedagogia do oprimido. São Paulo: Paz e Terra, 1994.

GERMANO, R.M. Educação e ideologia da Enfermagem no Brasil. 2.ed. São Paulo: Cortez, 1985.

HENRIQUES, R.L.M.; RODRIGUES, B.M.R. A formação e a qualidade política do enfermeiro. J. ABEn, v.45, n.1, p.5, 2003.

KRUSE, M.H.L.; MEYER, D.E. Acerca das Diretrizes Curriculares e projetos pedagógicos: um início de reflexão. In: SEMINÁRIO NACIONAL DE DIRETRIZES PARA A EDUCAÇÃO EM ENFERMAGEM, 6., 2002, Teresina. Anais... Teresina, 2002. (mimeogr.).

MEDEIROS, R.M. et al. Construção de competências em Enfermagem. Caxias do Sul: Educs, 2001. (Coleção Conexão)

MINAYO, M.C.S. O desafio do conhecimento: pesquisa qualitativa em saúde. 6.ed. São Paulo: Hucitec, 1999

REBOUL, O. O que é aprender. Coimbra: Livraria Almedina, 1982.

REDE UNIDA. A construção de modelos inovadores de ensino-aprendizagem: as lições aprendidas pela Rede Unida. Rev. Div. Saude Debate, n.22, p.49-62, 2000.

SENA-CHOMPRÉ, R.R.; EGRY, E.Y. A enfermagem no Projeto UNI: redefinindo um novo projeto político para a enfermagem brasileira. São Paulo: Hucitec, 1998.

TEÓFILO, T.J.S.; DIAS,M.S.E. Concepciones de docentes y discentes respecto a metodologías de enseñanza - aprendizaje: análisis del caso del Curso de Enfermería de la Universidad Estatal Vale do Acaraú en Sobral, estado de Ceará, Brasil. Interface - Comunic., Saude, Educ., v.13, n.30, p.137-51, jul./set. 2009.

Este estudio trata de conocer la concepción de docentes y discentes en el Curso de Enfermería de la Universidad Estatal Vale do Acaraú acerca de metodologías de enseñaza - aprendizaje. La colecta de datos ha sido por medio de grupos focales con estudiantes y profesores y observación participante en sala de aula entre junio y julio de 2006 . El análisis se orientó por el referencial de la hermenéutica - dialéctica. Los discursos han revelado que manifestaciones de poder intermedian la relación pedagógica. El análisis de divergencias y convergencias entre los discursos revela que, mientras las primeras se insertan en el campo epistemológico, las segundas provienen del cotidiano de las prácticas. Se infiere la necesidad de incorporación de metodologías activas y de una relación dialógica que permite superar el poder establecido y la disonancia entre teoría y práctica.

Palabras clave: Educación superior. Educación en Enfermería. Metodologías de enseñanza - aprendizaje.

Recebido em 03/07/2008. Aprovado em 13/10/2008 
